\title{
A sustainable process for the recovery of volatile constituents from Gracilaria lemaneiformis in agar production and evaluation of their antioxidant activities
}

\author{
Shengliang Yuan ${ }^{1 \dagger}$, Kefeng Wu ${ }^{1 \dagger}$, Zhihong Duan ${ }^{1}$, Yanxia Huang ${ }^{1}$, Yingnian $\mathrm{Lu}^{1 *}$ (D) and Xiaoli Ma ${ }^{2}$
}

\begin{abstract}
Background: Gracilaria lemaneiformis is a common red alga used as a raw material source for the agar industry. Its extract is rich in natural volatile constituents (VCs) having antioxidant activities. Herein, a sustainable method was used to recover VCs from the alga. The chemical composition of VCs present in the $n$-hexane fraction was analyzed by gas chromatography-mass spectroscopy (GC-MS) and the antioxidant potential was measured using a series of in vitro biochemical assays, including DPPH, hydroxyl, and superoxide radical scavenging assays.
\end{abstract}

Results: The recovery yield of the VCs was 0.823 wt\% of the dry mass of G. lemaneiformis. A total of $25 \mathrm{VCs}$ were successfully identified, comprising approximately $99.94 \%$ of the total volume. The major component was $n$-hexadecanoic acid (38.57\%), followed by oleic acid (25.48\%), arachidonic acid (12.84\%), and tetradecanoic acid (2.52\%). In addition, The VCs displayed strong free radical scavenging activity in the DPPH $\left(I C_{50}=21.56 \mathrm{mg} / \mathrm{L}\right)$, hydroxyl $\left(I C_{50}=18.34 \mathrm{mg} / \mathrm{L}\right)$, and superoxide $\left(I C_{50}=391.12 \mathrm{mg} / \mathrm{L}\right)$ radical scavenging assays. The antioxidant activities of the VCs exhibited a dosedependence at concentrations ranging from 5 to $200 \mathrm{mg} / \mathrm{L}$.

Conclusion: The results indicated that the sustainable process improved the agar quality and that the extract contained many natural VCs with antioxidant activities, which have the potential to be used in functional food and cosmetics instead of as a discarded byproduct of the agar industry.

Keywords: Gracilaria lemaneiformis, Volatile constituents, Sustainable extraction, Antioxidant, GC-MS

\section{Introduction}

Gracilaria lemaneiformis (G. lemaneiformis) a species of Gracilariales, is abundantly cultivated along the coast of China due to its high commercial value [1]. This seaweed is edible as a sea-flavor vegetable [2], and is also used as a traditional Chinese medicine because of its abundant ingredients beneficial for human health $[3,4]$. More importantly, this seaweed is used in the agar industry as a raw material because of its high polysaccharide content $[5,6]$. In current agar production, dried seaweed is used

\footnotetext{
*Correspondence: lyn7591@hotmail.com

†Shengliang Yuan and Kefeng Wu contributed equally to this work

${ }^{1}$ Guangdong Key Laboratory for Research and Development of Natural

Drugs, Guangdong Medical University, Zhanjiang 524023, China

Full list of author information is available at the end of the article
}

as a raw material to produce agar via several methods including alkali pretreatment or acid hydrolysis [7, 8], and the volatile constituents (VCs) of G. lemaneiformis are destroyed and discarded as waste. The VCs of G. lemaneiformis are reported to exhibit cytotoxic activity and tyrosine phosphatase $1 \mathrm{~B}$ inhibitory activity $[9,10]$, suggesting that these VCs could be useful in the food, cosmetic, and pharmaceutical industries [11, 12]. Therefore, it is worthwhile to recover VCs to improve the economic value of G. lemaneiformis.

VCs are composed of significant amounts of lipids that exhibit biological activities such as antioxidant, antitumor, anti-Rhizopus activities [13-15]. For these applications, natural antioxidants have attracted significant research attention. Compared to synthetic antioxidants, 
safe and inexpensive natural antioxidants are more popular with consumers. Many studies have reported that antioxidant compounds are effective for protecting human health and food safety against the oxidizing reactions by reactive oxygen species (ROS). Excessive production of ROS causes oxidative stress which damages cell structure, leading to a number of chronic diseases including stroke, cancer, diabetes, atherosclerosis, and other degenerative diseases $[16,17]$. Therefore, there is significant demand for effective natural antioxidant VCs that exhibit strong antioxidant activity to eliminate the ROS and other free radicals. However, few studies have investigated the VCs from the edible seaweed as important natural antioxidants and flavor agents in food industry.

In this study, a sustainable method was developed for the recovery of VCs from the red algae G. lemaneiformis. The chemical composition of VCs present in the $n$-hexane fraction was analyzed by GC-MS: gas chromatography-mass spectroscopy. In addition, the antioxidant activities of the extracted VCs were evaluated by a series of biochemical assays in vitro including the DPPH, hydroxyl, and superoxide radical scavenging assays. The sustainable extraction process of VCs improved agar quality and reduced the amount of effluent, providing a source of natural antioxidants rather than waste.

\section{Methods}

\section{Biological material}

Red seaweed, G. lemaneiformis, was harvested in June 2016 from the Zhanjiang Naozhou coastline of Guangdong province (N 21 $12^{\prime}$; E $110^{\circ} 4^{\prime}$ ) in Southern China. The seaweed was washed thoroughly with tap water to remove salt and impurities and subsequently air-dried at $60{ }^{\circ} \mathrm{C}$. The dried sample was cut and mixed with a blender and stored in a refrigerator at $4{ }^{\circ} \mathrm{C}$ until use. The sample was identified by the School of Marine Science, Guangdong Ocean University, China.

\section{Chemicals and reagents}

1,1-Diphenyl-2-picrylhydrazyl (DPPH) was purchased from Tokyo Kasei Kogyo Co., Ltd. (Tokyo, Japan). The hydroxyl radical and superoxide anion detection kits were obtained from the Nanjing Jiancheng Bioengineering Institute (Nanjing, China). Deionized water was supplied by a Milli-Q water purification system from Millipore (USA). All other reagents used in this study were of analytical grade.

\section{Sustainable extraction for the recovery of VCs}

The natural VCs were extracted as previously described [10] with some modifications. Briefly, the dry G. lemaneiformis $(150 \mathrm{~g})$ was mixed with $70 \%$ ethanol $(3000 \mathrm{~mL})$ and ultrasonically pretreated $10 \mathrm{~min}$, and then the mixture was refluxing at $80^{\circ} \mathrm{C}$ for $2 \mathrm{~h}$. After twice extractions, the extracts were combined and concentrated using a rotary evaporator at $40{ }^{\circ} \mathrm{C}$. The crude extract was dissolved in deionized water and fractioned with $n$-hexane. Subsequently, the $n$-hexane fraction was concentrated using a rotary evaporator to recovery the solvent and obtain the VCs.

\section{Analysis of VCs by GC-MS}

The chemical constituents of the VCs from G. lemaneiformis were determined via GC-MS using a standard procedure [18]. The system was equipped with an Agilent 6890 gas chromatograph/5973 N mass selective detector (Palo Alto, Calif.) and separated using an HP-FFAP (HPfree fatty acid phase) capillary column $(30 \mathrm{~m} \times 0.25 \mathrm{~mm}$ i.d.; film thickness $=0.25 \mu \mathrm{m}$ ). Helium was used as the

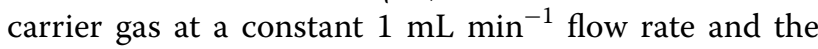
oven temperature was set at $50{ }^{\circ} \mathrm{C}$ for $5 \mathrm{~min}$, raised to $230{ }^{\circ} \mathrm{C}$ at $4{ }^{\circ} \mathrm{C} \mathrm{min}^{-1}$, and held for $20 \mathrm{~min}$. The detector and injector temperatures were maintained at $250{ }^{\circ} \mathrm{C}$. The ionizing energy of the mass selective detector was set at $70 \mathrm{eV}$, with a scanning mass range of $\mathrm{m} / \mathrm{z} 50-500$. The VCs sample $(1 \mu \mathrm{L}$ of 100 times-diluted samples in methanol) was pass through a splitless injector in manual mode. The relative percentages of the constituents of the VCs were expressed as percentages calculated from the normalized peak areas. The various chemical constituents of VCs were identified by GC retention times on a DB-5 capillary column, similarity index, and mass spectra, which were consistent with the mass spectra in the computer library (Wiley 275L program). Chromatographic peaks were checked with the mass chromatograms of the characteristic fragment ion peaks for homogeneity. The chemical structures of the dominant compounds were drawn using ACD software.

\section{Antioxidant activities \\ DPPH radical scavenging activity}

The DPPH radical scavenging activity assay was used to determine the antioxidant activity of the isolated VCs. The assay was performed according to a method previously described with slight modifications [19]. Briefly, a sample aliquot $(100 \mu \mathrm{L})$ was mixed with $100 \mu \mathrm{L}$ of $0.2 \mathrm{mM}$ DPPH ethanol solution and the intermixture was incubated at room temperature for $30 \mathrm{~min}$. The sample absorbance was measured at $517 \mathrm{~nm}$. All experiments were performed in triplicate and the percentage of scavenged DPPH was calculated using the following equation:

DPPH scavenging activity $(\%)=\left[\left(\mathrm{A}_{\mathrm{C}}-\mathrm{A}_{\mathrm{S}}\right) / \mathrm{A}_{\mathrm{C}}\right] \times 100$ where $A_{c}$ is the absorbance value of the control (mixture of $100 \mu \mathrm{L}$ DPPH solution and $100 \mu \mathrm{L}$ ethanol) and $A_{s}$ is 
the absorbance value of the sample. Vitamin $C$ was used as a positive reference.

\section{Hydroxyl radical scavenging activity}

Hydroxyl radical (HOR) scavenging activity of the VCs was determined according to a previously described method with some modification [19]. Briefly, $1.0 \mathrm{~mL}$ of a ferrous sulfate solution $(6.0 \mathrm{mM}), 1.0 \mathrm{~mL}$ hydrogen peroxide $(6.0 \mathrm{mM}), 0.5 \mathrm{~mL}$ salicylic acid $(2.0 \mathrm{mM})$, and $1.0 \mathrm{~mL}$ sample solutions (at various concentrations) were thoroughly mixed and incubated at room temperature for $40 \mathrm{~min}$. The mixture absorbance was then measured at $550 \mathrm{~nm}$ and vitamin $\mathrm{C}$ was used as a positive control. The hydroxyl radical scavenging activity was calculated using the following equation:

HOR scavenging activity $\%=\left[\left(\mathrm{A}_{1}-\mathrm{A}_{2}\right) /\left(\mathrm{A}_{1}-\mathrm{A}_{0}\right)\right]$

$$
\times 100 \text {; }
$$

where $A_{0}$ is the absorbance value of the reagent blank, $A_{1}$ is the positive control absorbance, and $\mathrm{A}_{2}$ is the absorbance value of the sample.

\section{Superoxide radical scavenging activity}

The superoxide anion radical (SOAR) scavenging activity of the VCs was measured using the procedure described previously with some modifications [20]. All solutions were prepared in $0.2 \mathrm{M}$ phosphate buffer $(\mathrm{pH}$ 7.4). The reaction mixture consisted of $0.5 \mathrm{~mL}$ of the reaction buffer solution ( $\mathrm{pH} 7.4), 100 \mu \mathrm{L}$ PMS $(15 \mu \mathrm{M})$, $100 \mu \mathrm{L} \mathrm{NADH}(73 \mu \mathrm{M}), 100 \mu \mathrm{L} \mathrm{NBT}(50 \mu \mathrm{M})$, and 200 $\mu \mathrm{L}$ sample of various concentrations completely blended and incubated at room temperature for $30 \mathrm{~min}$ and the absorbance was measured at $550 \mathrm{~nm}$. The control was a mixture without any sample and the assay was performed in triplicate. The superoxide anion radical scavenging activity (\%) was analyzed using the following equation:

SOAR scavenging activity $(\%)=\left[1-\left(\mathrm{A}_{\mathrm{S}} / \mathrm{A}_{\mathrm{C}}\right)\right] \times 100$,

Vitamin $C$ was used as a reference.

\section{Statistical analysis}

The data were analyzed using a one-way analysis of variance (ANOVA) followed by the Duncan's test (SPSS 12.0, SPSS Inc., USA). The data are expressed as mean \pm standard deviation. All experiments were performed in triplicate and $\mathrm{p}<0.05$ was considered statistically significant.

\section{Results and discussion}

\section{Recovery yield of VCs from G. lemaneiformis}

To manufacture high quality agar from G. lemaneiformis, many redundant constituents such as fatty acids, essential oils and pigments should be removed. However, it may be beneficial to recovery the VCs from the raw material seaweed as natural antioxidants. In this study, using the reflux condensing extraction shown in Fig. 1, the recovery yield of the VCs was $0.823 \mathrm{wt} \%$ on a dry basis from G. lemaneiformis. The recovery of VCs was lower for seaweeds such as $P$. tenera (1.41\%) obtained by the hydrodistillation [21], but higher than that of $U$. pinnatifida $(0.260 \%)$ obtained by microwave-assisted hydro-distillation [22]. The differing results of the various seaweeds can be attributed to species-specific factors, environmental differences, as well as varied extraction methods and conditions such as solvents, times, and temperatures [23] used. Therefore, it was valuable to recover and further analyze the chemical constituents of the VCs obtained from red seaweed. In this extraction process, the VCs of G. lemaneiformis were obtained and ethanol was recovered, the seaweed was next used as raw material to produce agar. All solvents can be recovered and recycled, this result showed no harmful pollutant was release into the environment and it was a green sustainable process.

\section{GC-MS analysis of VCs in the $\boldsymbol{n}$-hexane fraction}

The chemical constituents of VCs were identified via GC-MS and the results are shown in Table 1 and Fig. 2. A total of 25 volatile constituents were successfully identified comprising $99.94 \%$ of the total volume. The major constituents of the VCs obtained from G. lemaneiformis were $n$-hexadecanoic acid (38.57\%), oleic acid (25.48\%), arachidonic acid (12.84\%), cholesterol (4.90\%), tetradecanoic acid $(2.52 \%)$. It was clear that $n$-hexadecanoic acid and tetradecanoic acid was non-reducing saturated fatty acid, in contrast, oleic acid, arachidonic acid and cholesterol was reductive.

The $n$-hexadecanoic acid content was the highest (38.57\%), nearly twice as high as the maximum content of $n$-hexadecanoic acid (20.08\%) in $n$-hexane extracted previously from the same type of seaweed [10]. It has been reported that $n$-hexadecanoic acid exhibits various biological activities including anti-inflammatory activities, anticancer effects, and antioxidant properties [24, 25].

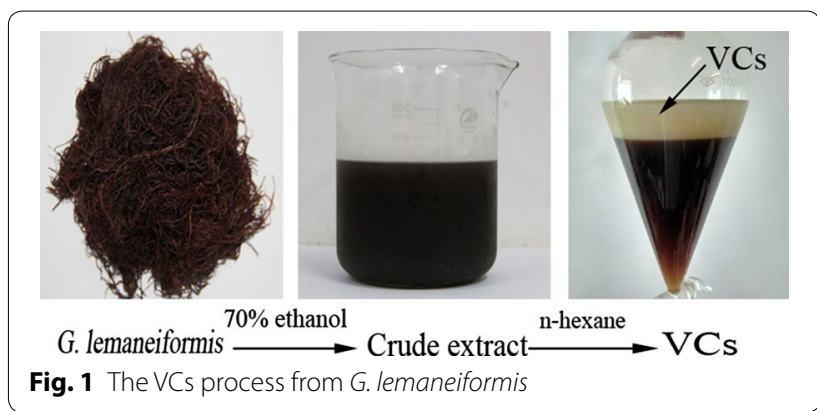


Table 1 VCs identified by GC-MS in the $n$-hexane fraction of G. lemaneiformis

\begin{tabular}{|c|c|c|c|}
\hline No. & RT & RPA (\%) & Compound \\
\hline 1 & 3.833 & 0.21 & Hexanal \\
\hline 2 & 7.232 & 0.21 & Undecane \\
\hline 3 & 17.026 & 0.20 & Heptadecane \\
\hline 4 & 17.789 & 2.52 & Tetradecanoic acid \\
\hline 5 & 17.989 & 0.21 & Cyclopropanecarboxylic acid, 2,2-dimethyl-3- \\
\hline 6 & 18.589 & 0.39 & Nonadecane \\
\hline 7 & 18.801 & 0.53 & Pentadecanoic acid \\
\hline 8 & 19.665 & 1.69 & cis-9-Hexadecenoic acid \\
\hline 9 & 19.802 & 3.05 & Dibutyl phthalate \\
\hline 10 & 20.131 & 38.57 & $n$-Hexadecanoic acid \\
\hline 11 & 20.300 & 0.87 & Hexadecanoic acid \\
\hline 12 & 20.408 & 0.57 & Isopropyl palmitate \\
\hline 13 & 21.275 & 1.05 & Phytol \\
\hline 14 & 21.392 & 0.25 & 13,16-Octadecadiynoic acid, methyl ester \\
\hline 15 & 21.716 & 25.48 & Oleic acid \\
\hline 16 & 22.267 & 1.01 & Isopropyl stearate \\
\hline 17 & 23.150 & 12.84 & Arachidonic acid \\
\hline 18 & 23.583 & 0.99 & 9-Octadecenamide, (Z)- \\
\hline 19 & 23.717 & 0.50 & Hexanedioic acid, bis(2-ethylhexyl) ester \\
\hline 20 & 23.933 & 0.46 & 3-Butenoic acid, 2-oxo-4-phenyl- \\
\hline 21 & 24.789 & 1.52 & Hexadecanoic acid, 2-hydroxy-1-(hydroxymethyl \\
\hline 22 & 25.565 & 0.59 & 2-Nitrophenylcinnamamide \\
\hline 23 & 25.833 & 0.27 & Arachidonic acid \\
\hline 24 & 32.467 & 4.90 & Cholesterol \\
\hline 25 & 33.633 & 1.06 & Cholest-5-en-3-ol, (3.beta.,5.alpha.) \\
\hline Total identified & & 99.94 & \\
\hline
\end{tabular}

The compounds were numbered in order of elution; RT, retention time (min); RPA, relative peak area

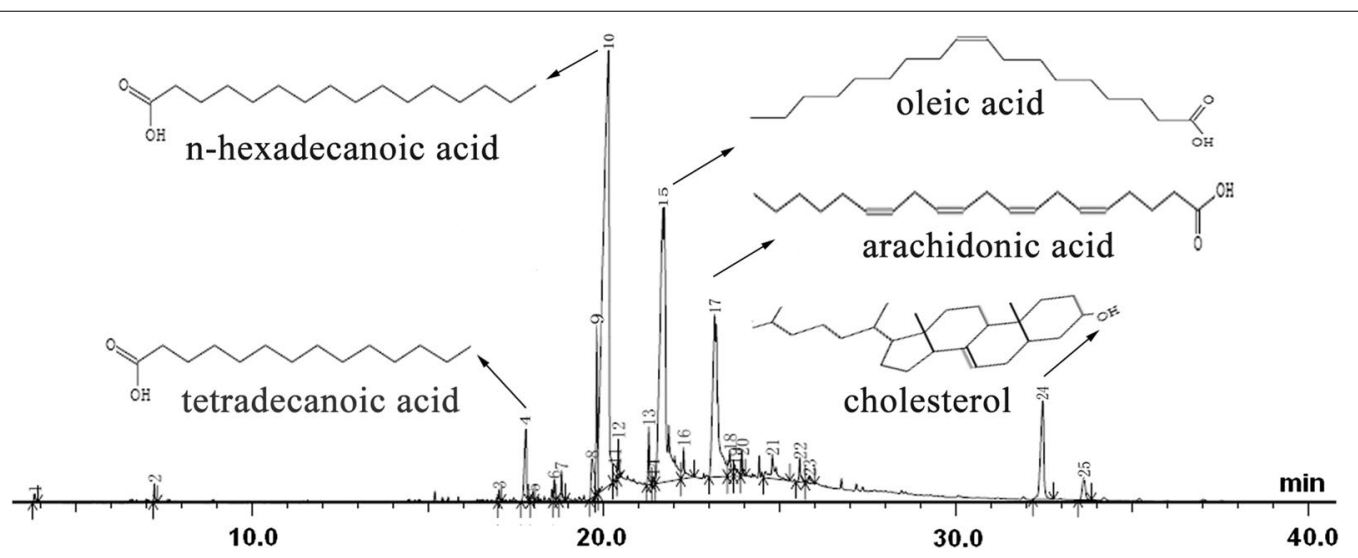

Fig. 2 GC-MS spectra of VCs present in the $n$-hexane fraction and chemical structures of the five dominant compounds

Tetradecanoic acid is commonly called myristic acid and is found in seaweeds such as edible kelps [26]. The tetradecanoic acid content was significant different in different alga including G. lemaneiformis (2.52\%) (shown in Table 1), L. japonica (51.75\%) [18], and $U$. pinnatifida (31.32\%) [22]. Tetradecanoic acid has been reported to possess potential antibacterial activity [27]; it is also 
Table 2 Recovery yield and antioxidant activities of the VCs

\begin{tabular}{|c|c|c|c|c|}
\hline \multirow[t]{2}{*}{ Sample } & \multirow[t]{2}{*}{ Yield (\%) } & \multicolumn{3}{|l|}{$I C_{50}(\mathrm{mg} / \mathrm{L})^{a}$} \\
\hline & & $\begin{array}{l}\text { DPPH radical scavenging } \\
\text { activity }\end{array}$ & $\begin{array}{l}\text { Hydroxyl radical scavenging } \\
\text { activity }\end{array}$ & $\begin{array}{l}\text { Superoxide radical } \\
\text { scavenging activity }\end{array}$ \\
\hline VCs & 0.823 & $21.56 \pm 1.02$ & $18.34 \pm 1.81$ & $391.12 \pm 3.32$ \\
\hline Vitamin C & $\mathrm{N}$ & $4.25 \pm 1.0$ & $158.02 \pm 2.65$ & $108.28 \pm 2.12$ \\
\hline
\end{tabular}

All values are mean $\pm S D ; S D$ standard deviation

$N$ not tested

${ }^{a} \mathrm{IC}_{50}$ : Concentration of extract (mg/L) exhibiting $50 \%$ scavenging potential

applied as a flavoring agent in food industry, and a brain drug additive in medicine [18].

The total amounts (43.22\%) of oleic acid, arachidonic acids and cholestrol suggested that significant amounts of unsaturated ethylenic bonds $(\mathrm{C}=\mathrm{C})$ were present, therefore the VCs were imparted reductive properties. The antioxidant activity of the VCs can be ascribed to the donation of electrons to reactive oxygen radical, reducing them to more stable and non-reactive species. These polyunsaturated fatty acids represent a valuable natural source of antioxidants from seaweed extract $[28,29]$.

\section{Antioxidant activities}

To determine the antioxidant effects of the VCs, a number of in vitro antioxidant assays were performed including the $\mathrm{DPPH}$, hydroxyl, and superoxide radical scavenging assays. The $\mathrm{IC}_{50}$ values of these assays are provided in Table 2.

\section{DPPH radical scavenging activity}

As a free radical, DPPH has been extensively used to evaluate antioxidant activity of various compounds and their free radical scavenging activity. As shown in Fig. 3a, the DPPH radical scavenging of the VCs showed dosedependent characteristic at concentrations ranging from 5 to $200 \mathrm{mg} / \mathrm{L}$. The VCs exhibited scavenging activity by inhibiting the DPPH radical with an $\mathrm{IC}_{50}$ value of $21.56 \pm 1.02 \mathrm{mg} / \mathrm{L}$, compared with that of vitamin $\mathrm{C}$ was $4.25 \pm 1.0 \mathrm{mg} / \mathrm{L}$. The high DPPH radical scavenging activity of VCs can be attributed to the rich unsaturated fatty acid content, which included oleic acid and arachidonic acid, which are effective DPPH free radical scavengers [30]. These result suggested that many VCs with strong antioxidant activity were present in the G. lemaneiformis extracts.

\section{Hydroxyl radical scavenging activity}

The hydroxyl radical is strongly oxidizing, which can cause oxidative injury, cell damage, and death. Therefore, hydroxyl radical analysis has been widely accepted for evaluating free radical scavenging activity [31]. The hydroxyl radical scavenging potential of the VCs

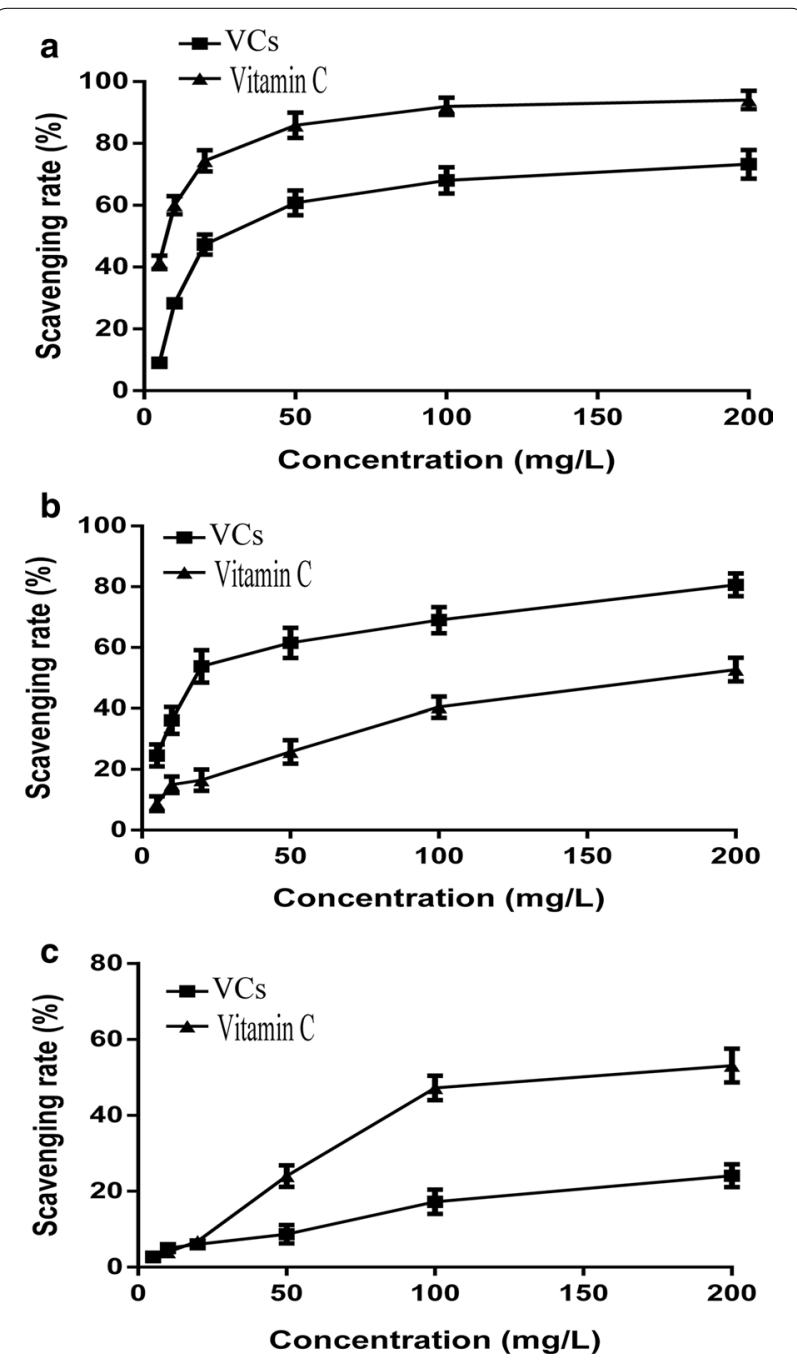

Fig. 3 Scavenging activity of the VCs extracted from G. lemaneiformis. Vitamin C was used as a positive control. a DPPH radical, $\mathbf{b}$ hydroxyl radical, and $\mathbf{c}$ superoxide radical assays (value $=$ mean $\pm S D ; n=3$ )

is shown in Fig. 3b. The VCs exhibited a concentration-dependent hydroxyl radical scavenging activity at concentrations ranging from 5 to $200 \mathrm{mg} / \mathrm{L}$. The hydroxyl radical scavenging activity of the $\mathrm{VCs}\left(\mathrm{IC}_{50}\right.$ 
$18.34 \pm 1.81 \mathrm{mg} / \mathrm{L}$ ) was higher than that of the positive reference vitamin $\mathrm{C}\left(\mathrm{IC}_{50} 158.02 \pm 2.65 \mathrm{mg} / \mathrm{L}\right)$. The antioxidant activity of the VCs can be ascribed to the donation of electrons from the VCs to reactive groups, reducing them to more stable and non-reactive species. Because of their high hydroxyl radical scavenging potential, the VCs may be used in an indicator role, acting efficiently against oxidative damage caused to various biomolecules [32], and applied as a food additive or preservative.

\section{Superoxide radical scavenging activity}

The superoxide anion is a weak oxidant and a precursor of ROS including singlet oxygen, the hydroxyl radi$\mathrm{cal}$, and hydrogen peroxide. It can combine with other reactive species, such as nitric oxide produced by macrophages, to afford more reactive species [33]. In this study, the VCs exhibited a concentration-dependent superoxide radical scavenging activity. In addition, the VCs contained a moderate superoxide radical scavenging activity with an $\mathrm{IC}_{50}$ value of $391.12 \pm 3.32 \mathrm{mg} / \mathrm{L}$, which was weaker than that of obtaining from $U$. pinnatifida $\left(\mathrm{IC}_{50} 260.89 \mathrm{mg} / \mathrm{L}\right)$ [22] and the positive reference vitamin $\mathrm{C}\left(\mathrm{IC}_{50} 108.28 \pm 2.12 \mathrm{mg} / \mathrm{L}\right)$. As shown in Fig. 3c, the superoxide radical scavenging potential of the VCs from G. lemaneiformis were indicative of their effective antioxidant activity.

\section{Conclusion}

In conclusion, VCs were recovered from the edible seaweed G. lemaneiformis commonly used in agar production using sustainable methods. In addition, the chemical constituents of the VCs were identified via GC-MS and shown to contain high contents of fatty acids, unsaturated fatty acids, aldehydes, sterols, and other types of beneficial compounds. The VCs exhibited antioxidant potential in terms of DPPH, hydroxyl, and superoxide radical scavenging activities. Thus, the VCs are effective natural antioxidants that can be utilized in various applications rather than discarded as agar industrial waste.

\footnotetext{
Abbreviations

G. lemaneiformis: Gracilaria lemaneiformis; VCs: volatile constituents; GC-MS: gas chromatography-mass spectroscopy; ROS: reactive oxygen species; DPPH: 1,1-diphenyl-2-picrylhydrazyl; HOR: hydroxyl radical; SOAR: superoxide anion radical; $\mathrm{RT}$ : retention time; RPA: relative peak area.
}

\section{Acknowledgements}

We were grateful to Prof. En-Yi Xie for identifying the G. lemaneiformis.

\section{Authors' contributions}

SLY and ZHD performed the experiments and wrote the manuscript. YNL and XLM conceived and designed the experiments; YXH and KFW helped in GC-

$\mathrm{MS}$ analysis. All authors read and approved the final manuscript.

\section{Funding}

This work was supported by the Science and Technology Planning Project of Guangdong Province, China (2018A030307001) and the Science \& Technology Special Project of Zhanjiang (2017A03020, 2015 A01032 and 2017A06012).

\section{Availability of data and materials}

The datasets used and/or analysed during the current study are available from the corresponding author on reasonable request.

\section{Competing interests}

The authors declare that they have no competing interests.

\section{Author details}

${ }^{1}$ Guangdong Key Laboratory for Research and Development of Natural Drugs, Guangdong Medical University, Zhanjiang 524023, China. ${ }^{2}$ Affiliated Hospital, Guangdong Medical University, Zhanjiang 524023, China.

Received: 24 December 2017 Accepted: 11 May 2019

Published online: 31 May 2019

\section{References}

1. Jin M, Liu H, Hou Y, Chan Z, Di W, Li L, Zeng R (2017) Preparation, characterization and alcoholic liver injury protective effects of algal oligosaccharides from Gracilaria lemaneiformis. Food Res Int 100:186-195

2. Wen X, Peng C, Zhou H, Lin Z, Lin G, Chen S, Li P (2006) Nutritional composition and assessment of Gracilaria lemaneiformis Bory. J Integr Plant Biol 48:1047-1053

3. Fan Y, Wang W, Song W, Chen H, Teng A, Liu A (2012) Partial characterization and anti-tumor activity of an acidic polysaccharide from Gracilaria Lemaneiformis. Carbohydr Polym 88:1313-1318

4. Fan YL, Wang WH, Chen HS, Liu N, Liu AJ (2012) In vitro and in vivo immunomodulatory activities of an acidic polysaccharide from Gracilaria lemaneiformis. Adv Mat Res 468-471:1941-1945

5. Meena R, Chaudhary JP, Agarwal PK, Maiti P, Chatterjee S, Raval HD, Agarwal P, Siddhanta AK, Prasad K, Ghosh PK (2014) Surfactant-induced coagulation of agarose from aqueous extract of Gracilaria dura seaweed as an energy-efficient alternative to the conventional freeze-thaw process. RSC Adv 4:28093-28098

6. Yuan S, Duan Z, Lu Y, Ma X, Wang S (2018) Optimization of decolorization process in agar production from Gracilaria lemaneiformis and evaluation of antioxidant activities of the extract rich in natural pigments. 3 Biotech 8:8

7. Li H, Yu X, Jin Y, Zhang W, Liu Y (2008) Development of an eco-friendly agar extraction technique from the red seaweed Gracilaria lemaneiformis. Bioresour Technol 99:3301-3305

8. Wang L, Shen Z, Mu H, Lin Y, Zhang J, Jiang X (2017) Impact of alkali pretreatment on yield, physico-chemical and gelling properties of high quality agar from Gracilaria tenuistipitata. Food Hydrocoll 70:356-362

9. Shaoling Y, Gang Y, Bo Q, Xianqing Y (2016) Analysis of volatile compounds of dried Gracilaria lemaneiformis by HS-SPME method (in China). South China Fish Sci 12:115-122

10. Guo X, Gu D, Wang M, Huang Y, Li H, Dong Y, Tian J, Wang Y, Yang Y (2017) Characterization of active compounds from Gracilaria lemaneiformis inhibiting the protein tyrosine phosphatase 1B activity. Food Funct 8:3271-3275

11. Cheng C, You-Chi H, Jun H, Shan L, Yang L, Ming-Yue Z (2011) Analysis of supercritical $\mathrm{CO}_{2}$ extract from Gracilaria lemaneiformis and its application in cigarett (in China). Tob Sci Technol 285:33-36

12. Chen K, Rios JJ, Perez-Galvez A, Roca M (2017) Comprehensive chlorophyll composition in the main edible seaweeds. Food Chem 228:625-633 
13. López V, Akerreta S, Casanova E, Garcia-Mina JM, Cavero RY, Calvo M (2007) In vitro antioxidant and anti-rhizopus activities of Lamiaceae herbal extracts. Plant Foods Hum Nutr 62:151-155

14. Wang X, Xie K, Zhuang H, Ye R, Fang Z, Feng T (2015) Volatile flavor compounds, total polyphenolic contents and antioxidant activities of a China gingko wine. Food Chem 182:41-46

15. Gallego MG, Gordon MH, Segovia FJ, Skowyra M, Almajano MP (2013) Antioxidant properties of three aromatic herbs (rosemary, thyme and lavender) in oil-in-water emulsions. J Am Oil Chem Soc 90:1559-1568

16. Lo'pez-Tinoco C, Roca M, Garcia-Valero A, Murri M, Tinahones FJ, Segundo C, Bartha JL, Aguilar-Diosdado M (2013) Oxidative stress and antioxidant status in patients with late-onset gestational diabetes mellitus. Acta Diabetol 50:201-208

17. Al-Gubory KH (2014) Environmental pollutants and lifestyle factors induce oxidative stress and poor prenatal development. Reprod Biomed Online 29:17-31

18. Patra JK, Das G, Baek KH (2015) Chemical composition and antioxidant and antibacterial activities of an essential oil extracted from an edible seaweed, Laminaria japonica L. Molecules 20:12093-12113

19. Cho M, Kang II-Jun, Won M-H, Lee H-S, You S (2010) Antioxidant activities of ethanol extracts and their solvent partitioned fractions from various green seaweeds. J Med Food 13:1232-1239

20. Duan X, Wu G, Jiang Y (2007) Evaluation of the antioxidant properties of litchi fruit phenolics in relation to pericarp browning prevention. Molecules 12:759-771

21. Patra JK, Lee S-W, Kwon Y-S, Park JG, Baek K-H (2017) Chemical characterization and antioxidant potential of volatile oil from an edible seaweed Porphyra tenera (Kjellman, 1897). Chem Cent J 11:34

22. Patra JK, Lee S-W, Park JG, Baek K-H (2017) Antioxidant and antibacterial properties of essential oil extracted from an edible seaweed Undaria pinnatifida. J Food Biochem 41:e12278

23. Cho M, Lee H-S, Kang I-J, Won M-H, You S (2011) Antioxidant properties of extract and fractions from Enteromorpha prolifera, a type of green seaweed. Food Chem 127:999-1006

24. Aparna V, Dileep KV, Mandal PK, Karthe P, Sadasivan C, Haridas M (2012) Anti-inflammatory property of $n$-hexadecanoic acid: structural evidence and kinetic assessment. Chem Biol Drug Des 80:434-439
25. Arora N, Pandey-Rai S (2014) GC-MS analysis of the essential oil of Celastrus paniculatus Willd. seeds and antioxidant, anti-inflammatory study of its various solvent extracts. Ind Crops Prod 61:345-351

26. Kajiwara T, Hatanaka A, Kawai T, Ishihara M, Tsuneya T (1988) Study of flavor compounds of essential oil extracts from edible Japanese kelps. J Food Sci 53:960-962

27. Seanego CT, Ndip RN (2012) Identification and antibacterial evaluation of bioactive compounds from Garcinia kola (Heckel) seeds. Molecules 17:6569-6584

28. Horincar VB, Parfene G, Tyagi AK, Gottardi D, Dinică R, Guerzoni ME, Bahrim G (2013) Extraction and characterization of volatile compounds and fatty acids from red and green macroalgae from the Romanian Black Sea in order to obtain valuable bioadditives and biopreservatives. J Appl Phycol 26:551-559

29. Mohy El-Din SM, El-Ahwany AMD (2016) Bioactivity and phytochemical constituents of marine red seaweeds (Jania rubens, Corallina mediterranea and Pterocladia capillacea). J Taibah Univ Sci 10:471-484

30. Patra JK, Kim SH, Baek K-H (2015) Antioxidant and free radical-scavenging potential of essential oil from Enteromorpha linza L. prepared by microwave-assisted hydrodistillation. J Food Biochem 39:80-90

31. Qiao D, Ke C, Hu B, Luo J, Ye H, Sun Y, Yan X, Zeng X (2009) Antioxidant activities of polysaccharides from Hyriopsis cumingii. Carbohydr Polym 78:199-204

32. Sowndhararajan K, Kang SC (2013) Free radical scavenging activity from different extracts of leaves of Bauhinia vahlii Wight \& Arn. Saudi J Biol Sci 20:319-325

33. Souza BWS, Cerqueira MA, Bourbon Al, Pinheiro AC, Martins JT, Teixeira JA Coimbra MA, Vicente AA (2012) Chemical characterization and antioxidant activity of sulfated polysaccharide from the red seaweed Gracilaria birdiae. Food Hydrocoll 27:287-292

\section{Publisher's Note}

Springer Nature remains neutral with regard to jurisdictional claims in published maps and institutional affiliations.
Ready to submit your research? Choose BMC and benefit from:

- fast, convenient online submission

- thorough peer review by experienced researchers in your field

- rapid publication on acceptance

- support for research data, including large and complex data types

- gold Open Access which fosters wider collaboration and increased citations

- maximum visibility for your research: over $100 \mathrm{M}$ website views per year

At BMC, research is always in progress.

Learn more biomedcentral.com/submissions 